\title{
Новое правовое регулирование института конституционной жалобы в Российской Федерации: тенденции и проблемы
}

\author{
Брежнев О.В. \\ Курская академия государственной и муниципальной службы, \\ Россия, 305044, г. Курск, ул. Станционная, 9 \\ E-mail: obrezhnev@yandex.ru
}

\begin{abstract}
Аннотация. На основе анализа широкого круга источников представлена авторская позиция относительно тенденций, связанных с совершенствованием законодательного регулирования института конституционной жалобы в РФ. Автором выстраивается логическая цепь рассуждений, включающая в себя характеристику произошедших изменений регламентации исследуемого института, определение соответствующих позитивных и негативных следствий таких изменений на основе диалектической методологии. Сделаны выводы о последовательной реализации законодателем подхода к конституционной жалобе как особому, экстраординарному средству защиты прав и свобод граждан, который реализуется субсидиарно: лишь тогда, когда иные способы защиты (в т. ч. судебной) не привели к восстановлению нарушенных прав. Одновременно обосновывается точка зрения о том, что правовые позиции Конституционного Суда РФ, касающиеся интерпретации отдельных элементов института конституционной жалобы, выраженные в его решениях, также служат своеобразным ориентиром для законодателя при разработке новых норм в исследуемой области.
\end{abstract}

Ключевые слова: конституция, конституционная жалоба, законодательство, правосудие, контроль, права, свободы, защита.

Для цитирования: Брежнев О.В. 2021. Новое правовое регулирование института конституционной жалобы в Российской Федерации: тенденции и проблемы. NOMOTHETIKA: Философия. Социология. Право, 46(2): 336-342. DOI 10.52575/2712-746X-2021-46-2-336-342

\section{New legal regulation of the institution of constitutional complaint in the Russian Federation: trends and problems}

\author{
Oleg V. Brezhnev \\ Kursk Academy of State and Municipal Service, \\ 9 Stancionnaya St, Kursk, 305044, Russia \\ E-mail: obrezhnev@yandex.ru
}

\begin{abstract}
Based on the analysis of a wide range of sources, the article presents the author's position on the trends associated with the improvement of legislative regulation of the institution of constitutional complaint in the Russian Federation. The author build a logical chain of reasoning, which includes a characteristic of the changes that have occurred in the regulation of the institution under study, the determination of the corresponding positive and negative consequences of such changes on the basis of dialectical methodology. Conclusions are made about the consistent implementation by the legislator of the approach to a constitutional complaint as a special, extraordinary means of protecting the rights and freedoms of citizens, which is implemented subsidiary: only when other methods of protection (including judicial) did not lead to the restoration of violated rights. At the same time, the point of view is substantiated
\end{abstract}


that the legal positions of the Constitutional Court of the Russian Federation concerning the interpretation of individual elements of the institution of constitutional complaint, expressed in its decisions, also serve as a kind of guideline for the legislator when developing new norms in the area under study.

Keywords: constitution, constitutional complaint, legislation, justice, control, rights, freedoms, protection.

For citation: Brezhnev O.V. 2021. New legal regulation of the institution of constitutional complaint in the Russian Federation: trends and problems. NOMOTHETIKA: Philosophy. Sociology. Law series, 46(2): 336-342 (in Russian). DOI 10.52575/2712-746X-2021-46-2-336-342

\section{Введение}

Защита основных прав и свобод человека и гражданина является одной из целей деятельности высшего судебного органа конституционного контроля - Конституционного Суда Российской Федерации (далее - КС РФ). Достижение данной цели обеспечивается реализацией всех полномочий КС РФ. Но при этом Конституция РФ (п. «а» ч. 4 ст. 125) и Федеральный конституционный закон от 21 июля 1994 г. № 1-ФКЗ «О Конституционном Суде Российской Федерации» (далее - ФКЗ о КС РФ) предусматривают специальное полномочие по рассмотрению жалоб на нарушение конституционных прав и свобод граждан законами или иными нормативными актами, примененными в конкретном деле. Совокупность правовых норм, регламентирующих содержание и порядок реализации этого полномочия, образует институт конституционной жалобы [Петина, 2017].

Данный институт имеет двойственную правовую природу: с одной стороны, он обеспечивает защиту прав конкретного лица, являющегося заявителем, открывая возможность пересмотра принятых в отношении его конкретных судебных актов, а с другой стороны, способствует устранению из системы законодательства дефектных норм, конституционноправовому истолкованию положений нормативных актов, т.е. решению задач, выходящих за рамки вопросов, затрагивающих судьбу индивида или объединения граждан, подавшего жалобу, и имеющих, таким образом, общее значение. Жалобы составляют до 98 \% от числа всех обращений, поступающих в КС РФ.

Закон РФ о поправке к Конституции РФ от 14 марта 2020 г. № 1-ФКЗ «О совершенствовании регулирования отдельных вопросов организации и функционирования публичной власти», а также принятый в его развитие Федеральный конституционный закон от 9 ноября 2020 г. № 5-ФКЗ «О внесении изменений в Федеральный конституционный закон «О Конституционном Суде Российской Федерации» существенно реформировали институт конституционной жалобы [Чепунов, Болдырева, 2021]. Рассмотрим основные направления этого реформирования.

\section{Расширение предмета конституционной жалобы}

Ранее допускалась подача в КС РФ жалобы на нарушение конституционных прав и свобод граждан исключительно законом, примененным в конкретном деле. Иными словами, в жалобе могла оспариваться конституционность норм только федерального конституционного закона, федерального закона, конституции (устава) и закона субъекта РФ.

Однако КС РФ сформулировал несколько правовых позиций, фактически расширяющих предмет конституционной жалобы. Он признавал допустимыми жалобы в отношении тех формально подзаконных нормативных правовых актов, которые по юридической силе тождественны закону. Например, указа Президента РФ, восполняющего пробелы в законодательном регулировании (по смыслу правовой позиции, изложенной в Постановлении КС РФ от 30 апреля 1996 г. № 11-П), постановления Государственной Думы об объявлении амнистии (Постановление КС РФ от 5 июля 2001 г. № 11-П). 
В Постановлении КС РФ от 27 января 2004 г. № 1-П была выражена правовая позиция, в соответствии с которой граждане вправе оспаривать в КС РФ конституционность норм постановлений Правительства РФ, находящихся в системном единстве с соответствующими нормами федерального закона, при условии, что в данном федеральном законе непосредственно предусмотрены полномочия Правительства РФ по изданию нормативных правовых актов по вопросам, не получившим содержательной регламентации в федеральном законе.

Конституционные изменения 2020 г. признают возможность подачи жалобы не только в отношении законов, но и нормативных актов Президента РФ, Совета Федерации, Государственной Думы, Правительства РФ, а также подзаконных нормативных актов законодательных и исполнительных органов государственной власти субъектов РФ с оговоркой о том, что эти акты (как и оспариваемые законы субъектов РФ) должны быть изданы по предметам ведения РФ или совместного ведения РФ и субъектов РФ [Брежнев, 2020].

Данная новелла, с одной стороны, расширяет возможности защиты прав граждан в КС РФ, но с другой - усиливает «конкуренцию» конституционной и административной судебных юрисдикций, ибо подзаконные нормативные акты высших органов власти могут являться предметом оспаривания и в судах общей юрисдикции в порядке административного судопроизводства [Велиева, Пресняков, 2020]. Эта «конкуренция» может стать особенно заметной с учетом того, что конституционные поправки 2020 г. фактически упразднили конституционные (уставные) суды субъектов РФ.

\section{Уточнение круга лиц, которые вправе обращаться с конституционными жалобами}

Ранее в ФКЗ о КС РФ (ч. 1 ст. 96) прямо предусматривалось право на обращение с конституционной жалобой граждан, их объединений, а также «иных органов и лиц, указанных в федеральном законе» (к ним относились Генеральный прокурор РФ и Уполномоченный по правам человека в РФ). КС РФ сформулировал ряд правовых позиций, существенно расширивших круг лиц, управомоченных на подобное обращение. Он, в частности, признал такое право за: иностранными гражданами и лицами без гражданства (Постановление от 17 февраля 1998 г. № 6-П); коммерческими организациями, обладающими статусом юридического лица, в т.ч. акционерными обществами, товариществами с ограниченной ответственностью (Постановление от 24 октября 1996 г. № 17-П); государственными унитарными предприятиями (Постановление от 12 октября 1998 г. № 24-П); образовательными учреждениями высшего образования (Постановление от 22 июня 2009 г. № 10-П); органами местного самоуправления (Постановление от 2 апреля 2002 г. № 7-П).

Внесение поправок от 9 ноября 2020 г. в ФКЗ о КС РФ обеспечивает «имплементацию» данных правовых позиций КС РФ в «ткань» законодательства о конституционном судопроизводстве. Теперь закон четко разделяет заявителей-жалобщиков на тех, кто обращается в защиту своих прав и свобод, нарушенных примененным нормативным актом (граждане, юридические лица и муниципальные образования в лице органов местного самоуправления), и тех, кто направляет жалобу в интересах иных граждан и юридических лиц (Уполномоченный по правам человека в РФ, уполномоченные по правам человека в субъектах РФ, другие уполномоченные по правам в отдельных сферах или отдельных категорий лиц, предусмотренные федеральными законами (по правам ребенка, по защите прав предпринимателей), иные органы и должностные лица в соответствии с федеральным законом, общероссийские организации, которые могут представлять интересы граждан и юридических лиц).

\section{Модификация условий допустимости конституционной жалобы}

Специальные условия допустимости конституционной жалобы предусмотрены ст. 97 ФКЗ о КС РФ. Реформа конституционного судопроизводства изменила их перечень и модифицировала содержание. 
Первое условие связано с наличием признаков нарушения прав и свобод заявителя или лица, в интересах которого подана жалоба. Ранее данное условие формулировалось иначе: если оспариваемый в жалобе закон затрагивает права и свободы граждан. Причем КС РФ воспринимал данное условие в системном единстве с нормой ч. 1 ст. 96 ФКЗ о КС РФ, которая указывала, что с конституционной жалобой обращаются граждане, «чьи права и свободы нарушаются» (в нынешней редакции ФКЗ о КС РФ - «по их мнению, нарушаются»). Отказывая в принятии к рассмотрению жалобы, КС РФ, как правило, констатировал, что оспариваемая норма не нарушает прав заявителя, хотя понятия «затрагивает» и «нарушает» применительно к правам и свободам граждан существенно отличаются по смыслу. Нынешние редакции положений ч. 1 ст. 96 и п. 1 ст. 97 ФКЗ о КС РФ более удачно сформулированы: они устраняют вышеуказанное противоречие.

Второе условие существенных изменений не претерпело: речь идет о том, что жалоба может быть подана в отношении нормативного правового акта, примененного в конкретном деле с участием заявителя или лица, в интересах которого подана жалоба. Хотя теперь ФКЗ о КС РФ прямо не указывает на то, что соответствующее дело должно быть завершено в суде, это логически вытекает из содержания других условий допустимости [Вилова, 2020].

Третье условие касается срока подачи обращения в КС РФ: жалоба может быть подана в течение 1 года после принятия судебного решения, которым исчерпываются внутригосударственные средства судебной защиты, а в случае, если в пересмотре дела судом, решение которого обычно исчерпывает такие средства по соответствующей категории дел, было отказано в связи с пропуском срока обжалования - не позднее 1 года после принятия последнего судебного решения, в котором был применен соответствующий нормативный акт. Годичный пресекательный срок подачи жалобы появился в российском конституционном судопроизводстве в 2014 г. Сейчас порядок его исчисления несколько уточнен. К сожалению, в данном случае не предусмотрена возможность восстановления пропущенного срока.

Наконец, четвертое условие является новым: оно требует исчерпанности всех внутригосударственных средств судебной защиты [Татаринов, 2021]. Это означает, по общему правилу, необходимость до обращения в КС РФ подачи «кассационной жалобы в суд максимально высокой для данной категории дел инстанции или в случае, если вступившие в силу судебные акты по данной категории дел подлежат обжалованию только в надзорном порядке, надзорной жалобы». Иными словами, по судебному делу, в связи с правоприменением по которому имеется намерение обратиться в КС РФ с жалобой, требуется до такого обращения, как минимум, подать вторую кассационную жалобу, а если речь идет о решении Верховного Суда РФ, принятом в первой инстанции, - направить надзорную жалобу. При этом КС РФ вправе отступить от этого правила в том случае, если придет к выводу о том, что «иное применение оспариваемого нормативного акта, чем имевшее место в конкретном деле, не предполагается». Обратим внимание также на то, что в соответствии с ч. 4 ст. 2 Федерального конституционного закона от 9 ноября 2020 г. № 5-ФКЗ в течение 6 месяцев с момента вступления в силу данного Закона действует более простое правило определения исчерпанности внутригосударственных средств судебной защиты, предполагающее, что для соблюдения данного условия достаточно просто подачи любой кассационной или (в случае с решением Верховного Суда РФ) надзорной жалобы.

\section{Усиление средств обеспечения производства по конституционной жалобе}

Как и ранее, в ФКЗ о КС РФ (ч. 1 ст. 98) предусмотрено, что КС РФ, приняв к рассмотрению жалобу на нарушение конституционных прав и свобод граждан, уведомляет об этом суд, принявший последнее судебное постановление по делу заявителя или лица, в интересах которого подана жалоба, а по требованию такого лица - орган, осуществляющий исполнение этого 
постановления, и суд, рассматривающий дело, для которого оно может иметь значение. Соответствующий суд вправе, хотя и не обязан приостановить исполнение судебного постановления или производство по делу до принятия решения КС РФ.

Теперь ФКЗ о КС РФ (ч. 2 ст. 98) предусматривает правомочие КС РФ в случае, если продолжение исполнения судебного решения по делу заявителя может привести к невозможности восстановления его прав, в определении о принятии жалобы к рассмотрению указать на необходимость приостановления исполнения судебного решения до вынесения постановления КС РФ и пересмотра конкретного дела, в котором был применен оспариваемый нормативный акт. Такое указание КС РФ приобретает уже обязательный характер для судов и органов, исполняющих судебные решения.

Таким образом, у КС РФ появилось более эффективное средство обеспечения производства по конституционной жалобе, создающее условия для последующего восстановления нарушенных прав граждан.

\section{Совершенствование механизма исполнения постановления КС РФ по жалобе гражданина}

По итогам рассмотрения дела о проверке конституционности нормативного правового акта в связи с жалобой гражданина КС РФ принимает одно из следующих постановлений: о признании оспариваемого акта или его части соответствующими Конституции РФ; о признании его соответствующим Конституции РФ в данном КС РФ истолковании; о признании его не соответствующим Конституции РФ (ч. 1 ст. 87, ч. 1 ст. 100 ФКЗ о КС РФ). Правовые последствия принятия каждого из этих решений соответственно носят такой же характер, как и по делам, связанным с запросами государственных органов и должностных лиц: сохранение юридической силы акта; возможность применения акта только с учетом его конституционно-правового смысла; утрата юридической силы акта [Винокуров, 2020].

Что касается воздействия постановления КС РФ на судьбу того судебного дела, в связи с которым последовало обращение в высший судебный орган конституционного контроля, то новое законодательное регулирование существенно усилило пределы усмотрения КС РФ в этой части (ст. 100 ФКЗ о КС РФ): в постановлении может быть указано на необходимость пересмотра дела заявителя в обычном порядке (ч. 2) либо возможность такого пересмотра после внесения изменений в правовое регулирование (ч. 3), а если пересмотр сам по себе не приведет к восстановлению нарушенных прав заявителя (ч. 4) - КС РФ вправе установить возможность использования в этих целях компенсаторных механизмов (форма и размер компенсации определяются судом, рассмотревшим в первой инстанции конкретное дело, в котором применен оспариваемый акт). Ранее КС РФ уже фактически использовал эти правомочия в своей практике, теперь они законодательно закреплены [Балаян, Сычев, 2020].

Отметим, что в отличие от ранее действовавшего регулирования, ФКЗ о КС РФ (ч. 3 ст. 79) теперь четко устанавливает те случаи, когда подлежат пересмотру судебные акты, связанные с применением неконституционной нормы или нормативного положения в истолковании, отличном от содержащегося в постановлении КС РФ, принятые в отношении лиц, не являвшихся заявителями в КС РФ: если соответствующее судебное решение не вступило в законную силу и подлежит проверке в апелляционной инстанции; при пересмотре дела в кассационной или надзорной инстанции в связи с кассационными или надзорными жалобами, представлениями, поданными по иным основаниям; если неконституционные положения послужили основанием для привлечения гражданина к уголовной или административной ответственности и др. [Ермаков, 2020] 


\section{Заключение}

Оценивая новое правовое регулирование института конституционной жалобы в РФ, необходимо отметить две тенденции, которые отчетливо прослеживаются в процессе совершенствования законодательства в данной области.

Во-первых, реализуется подход к институту конституционной жалобы как особому, экстраординарному средству защиты прав и свобод граждан, который применяется субсидиарно: лишь тогда, когда иные способы защиты (в т.ч. в судах общей юрисдикции и арбитражных судах) не привели к восстановлению нарушенных прав, т.е. оказались неэффективными. При этом расширились правозащитные возможности самого института конституционной жалобы, как в части круга оспариваемых актов, так и в отношении субъектов, управомоченных на обращение в КС РФ.

Во-вторых, законодатель закрепляет нормативно те правомочия КС РФ в исследуемой области, которые уже нашли отражение в практике его деятельности, согласуются с подходами, выраженными в его решениях. Таким образом, именно понимание КС РФ своей роли и предназначения в конкретном социально-историческом контексте выступает в качестве основы преобразований в сфере конституционного правосудия [Небратенко, 2020].

\section{Список литературы}

1. Балаян Э.Ю., Сычев С.С. 2020. Исполнение решений Конституционного Суда РФ по жалобам на нарушения конституционных прав и свобод граждан. Российская юстиция, 10: 31-33.

2. Брежнев О.В. 2020. Конституционная реформа 2020 г. и развитие конституционного правосудия в России. Конституционное и муниципальное право, 7: 3-6.

3. Велиева Д.С., Пресняков М.В. 2021. Реформа Конституционного Суда РФ 2020 г.: «кто будет сторожить сторожей». Конституционное и муниципальное право, 1: 12-22.

4. Вилова М.Г. 2020. Конституционное право на судебную защиту и некоторые принципы права: актуальные подходы к их соотношению. Государственная власть и местное самоуправление, 7: 3-7.

5. Винокуров В.А. 2020. Деятельность Конституционного Суда Российской Федерации: правовые пробелы и новые задачи. Конституционное и муниципальное право, 6: 24-29.

6. Ермаков Э.Ю. 2020. Юридические последствия судебного нормоконтроля требуют дальнейшего совершенствования. Российский судья, 7: 30-35.

7. Небратенко О.О. 2020. Правовая доктрина в деятельности Конституционного Суда Российской Федерации. Российский судья, 11: 27-31.

8. Петина М.М. 2017. Конституционная жалоба в системе средств защиты прав человека в России. Актуальные проблемы российского права, 12: 171-178.

9. Татаринов С.А. 2021. О конституционных новеллах регулирования статуса Конституционного Суда Российской Федерации. Государственная власть и местное самоуправление, 1: 39-44.

10.Чепунов О.И., Болдырева Е.В. 2021. К вопросу о конституционно-правовом совершенствовании публичной власти. NOMOTHETIKA: Философия. Социология. Право, 1: 170178.

\section{References}

1. Balayan E.YU., Sychev S.S. 2020. Ispolnenie reshenij Konstitucionnogo Suda RF po zhalobam na narusheniya konstitucionnyh prav i svobod grazhdan [Execution of decisions of the Constitutional Court of the Russian Federation on complaints of violations of the constitutional rights and freedoms of citizens]. Rossijskaya yusticiya, 10: 31-33.

2. Brezhnev O.V. 2020. Konstitucionnaya reforma 2020 g. i razvitie konstitucionnogo pravosudiya $\mathrm{v}$ Rossii [Constitutional reform in 2020 and the development of constitutional justice in Russia]. Konstitucionnoe i municipal'noe pravo, 7: 3-6. 
3. Velieva D.S., Presnyakov M.V. 2021. Reforma Konstitucionnogo Suda RF 2020 g.: «kto budet storozhit' storozhej» [Reform of the Constitutional Court of the Russian Federation in 2020: «who will guard the watchmen»]. Konstitucionnoe i municipal'noe pravo, 1: 12-22.

4. Vilova M.G. 2020. Konstitucionnoe pravo na sudebnuyu zashchitu i nekotorye principy prava: aktual'nye podhody $\mathrm{k}$ ih sootnosheniyu [Constitutional right to judicial protection and some principles of law: current approaches to their correlation]. Gosudarstvennaya vlast' i mestnoe samoupravlenie, 7: 3-7.

5. Vinokurov V.A. 2020. Deyatel'nost' Konstitucionnogo Suda Rossijskoj Federacii: pravovye probely i novye zadachi [Activities of the Constitutional Court of the Russian Federation: legal gaps and new challenges]. Konstitucionnoe i municipal'noe pravo, 6: 24-29.

6. Ermakov E.YU. 2020. YUridicheskie posledstviya sudebnogo normokontrolya trebuyut dal'nejshego sovershenstvovaniya [The legal consequences of judicial regulatory control require further improvement]. Rossijskij sud'ya, 7: 30-35.

7. Nebratenko O.O. 2020. Pravovaya doktrina v deyatel'nosti Konstitucionnogo Suda Rossijskoj Federacii [Legal doctrine in the activities of the Constitutional Court of the Russian Federation]. Rossijskij sud'ya, 11: 27-31.

8. Petina M.M. 2017. Konstitucionnaya zhaloba v sisteme sredstv zashchity prav cheloveka v Rossii [Constitutional complaint in the system of means of protection of human rights in Russia]. Aktual'nye problemy rossijskogo prava, 12: 171-178.

9. Tatarinov S.A. 2021. O konstitucionnyh novellah regulirovaniya statusa Konstitucionnogo Suda Rossijskoj Federacii [On Constitutional Novelties regulating the Status of the Constitutional Court of the Russian Federation.]. Gosudarstvennaya vlast' i mestnoe samoupravlenie, 1: 39-44.

10.CHepunov O.I., Boldyreva E.V. 2021. On the issue of constitutional and legal improvement of public power. NOMOTHETIKA: Filosofiya. Sociologiya. Pravo, 1: 170-178. (In Russian)

\section{ИНФОРМАЦИЯ ОБ АВТОРЕ}

Брежнев Олег Викторович, заведующий кафедрой конституционного и гражданского права ГОАУ ВО Курской области «Курская академия государственной и муниципальной службы», доктор юридических наук, профессор, г. Курск, Россия

\section{INFORMATION ABOUT THE AUTHOR}

Oleg V. Brezhnev, Head of the Department of Constitutional and Civil Law of the State Educational Autonomous Institution of Higher Education of the Kursk Region "Kursk Academy of State and Municipal Service", Doctor of Law, Professor, Kursk, Russia 